\title{
PLANNING SUNGANG-QUINGSHUIHE NEIGHBOURHOOD FOR A NEW INNOVATIVE GROWTH CENTRE OF SHENZHEN
}

\author{
B. HENK ${ }^{\mathrm{a}}, A . F \ddot{U} G E^{\mathrm{b}}, G Y . C S O M O ́ S^{\mathrm{c}}$ \\ Department of Civil Engineering, Faculty of Engineering, University of Debrecen, \\ H-4028 Debrecen, Ótemető u. 2-4, Hungary \\ ${ }^{a}$ E-mail: henkbence@gmail.com \\ bE-mail: attila.fuge@gmail.com \\ cE-mail: csomos@eng.unideb.hu
}

\begin{abstract}
Shenzhen is one of the most dynamically growing cities in the world with a population of more than 10 million. Situated in the Pearl River Delta (PRD) in China it is in the powerhouse of the global economy. Some decades ago Shenzhen was a small fishing village only, however, after its designation as a Special Economic Zone (SEZ) the city has gone through rapid urbanization and industrial development. Therefore, currently, Shenzhen is one of the leading economic hubs of China, an important gateway of the large Chinese economy, and a sub-provincial administrative centre in the PRD.

Sungang-Quingshuihe (SQ) is a neighbourhood of 2.5 square kilometres, in Louhu district in the east of Shenzhen. The landscape system of SQ has been largely destroyed and fragmented by developments. Our main goal is to redesign SQ neighbourhood for an innovative growth centre of Shenzhen. We envisage SQ as a liveable area with new and modern functions for international residents who work in higher education, information communication industry, medical services, R\&D facilities of multinational corporations, and research-oriented start-up companies. In order to accomplish this vision it is required to design new transportation system, public buildings, housing, green corridors and parklands.
\end{abstract}

Keywords: Shenzhen, Pearl River Delta, economic restructuring, planning, information \& communications technology

\section{Introduction}

According to the United Nations, Shenzhen was the 25 th largest megacity in terms of population in 2014 , but definitely the one of which population has shown the fastest increase (UN 2014). In 1986 Shenzhen's population was less than 200,000 (the neighbouring Hong Kong had more than 5 million inhabitants) when the first comprehensive plan was established with an ambitious goal of growing Shenzhen from a fishing village to a city of over one million population in 15 years (Chen and Kenney 2007, Zacharias and Tang 2010). The city needed five years only to reach the target and the large-scale expansion is still in progress: in 2014 the population of Shenzhen was 10.68 million, one-third larger than that of Hong Kong. The reason of this fast population growth is that in 1980 Shenzhen was designated as the first special economic zone (SEZ) by the Central Government and the State Council of Guangdong Province (Chen and Kenney 2007, Morrison 2014). According to Morrison (2014) the de- cision of the Central Government was primarily influenced by the fact that Shenzhen had a close proximity to Hong Kong. As a SEZ Shenzhen was given the status of free trade zone so that goods could be imported and exported without duty, in addition the city started to act as a base for the relocation of manufacturing from Hong Kong (Chen and Kenney 2007). Shenzhen became one of the fastest growing centres of low-cost manufacturing for export (Chen et al. 2014). From the designation of Shenzhen as SEZ the Pearl River Delta (PRD) gradually evolved into the main manufacturing region of China and a global power house (Lo and Yeung 2004) with such major cities as Guangzhou, Shenzhen, Zhuhai, Dongguan, Foshan, Huizhou in Guangdong Province, and Hong Kong.

In this megacity-region (Harrison and Hoyler 2015) Shenzhen has a special role as it is not only a sub-provincial administrative centre, but also the centre of advanced producer services (Yeh et al. 2014), large multinational corporations (Yang 2014), R\&D institutions and science parks (Chen and Kenney 2007, 
Cheng et al. 2014), leading regional banks and the Shenzhen Stock Exchange (Chen and Chen 2014). Furthermore, Shenzhen is one of the most important gateway cities of the Chinese economy. According to Shen (2014) "Shenzhen's export grew from US\$ 9.9 billion in 1991 to US\$ 25.5 billion in 1997 and US\$ 204.2 billion in 2010. It contributed $12.9 \%$ of the total export of China."

However, from 1993 significant restructuring has happened in the economy of Shenzhen. According to $\mathrm{Ng}$ (2003: 434) the "basic strategy is to develop Shenzhen into a modern world city with a prosperous economy, a stable and safe society, an amiable environment and a rational spatial layout with comprehensive infrastructure provision. Shenzhen is to be developed into a city with the 'environment of Singapore and efficiency of Hong Kong'. In 2009, the Shenzhen Municipal Government mapped out plans to promote the development of three new industries, biotechnology, new energy and the internet, which are considered to be the fundamental industries for Shenzhen's economic growth." Chen et al. (2014) state that since gaining its SEZ status "the industries in Shenzhen have shifted to computer software, information communication industry (ICT), microelectronics and components, electromechanical integration, and biotechnology. Shenzhen is an ICT hub, home to many electronic and hightech companies, both Chinese (e.g. Huawei, TCL) and foreign-owned (e.g. Foxconn). Furthermore, Shenzhen is a significant biotechnology centre, with the first firm in the world to obtain a drug license for a recombinant gene therapy." As a result of these processes - as Morrison (2014: 1545) argues - "the lowcost manufacturing is now no longer the backbone of Guangdong province's economy, where Shenzhen is located." Zacharias and Tang (2010) think that "Shenzhen provides the first signs of rapid de-industrialisation and restructuring in the boom environment of the PRD of Guangdong province."

Furthermore Shenzhen is one of the most important financial centres in China (Zhao et al. 2004, Chen et al. 2014, Chen and Chen 2014). It hosts the Shenzhen Stock Exchange, which primarily lists new firms in preparation for a new board for high-tech start-ups. According to Chen and Chen (2014) this "severely undermined the stock exchange's ability to attract capital. Compared to the Shanghai Stock Exchange, which mainly lists large-cap companies, the Shenzhen Stock Exchange focuses on small- and midcap enterprises. The Shenzhen Stock Exchange opened the ChiNext board, a NASDAQ-type exchange for high-growth, high-tech startups in 2009." Shenzhen is the headquarter of significant regional banks (China Merchants Bank, Ping An Bank), investment services firms (China Merchants Securities, CITIC Securities) and real estate companies (China Merchants Proper- ty Development, China Vanke, Gemdale). Chen and Chen (2014) state that Shenzhen as a financial centre is the competitor of Beijing, Shanghai and Hong Kong, while the Z/Yen Group based on its Global Financial Centres Index ranked Shenzhen 18th as compared to Shanghai 20th and Beijing 49th spot.

Shenzhen is the headquarter of large multinational corporations (listed by the annual Forbes 2000 ranking) including the automobile manufacturer BYD, the consumer electronic company Great Wall Technology, the information technology firm Tencent Holdings and the world's largest telecommunications equipment maker Huawei. Shenzhen is one of the most significant command and control centres in China (Brookings 2013): it was ranked 4th out of 51 Chinese cities in 2014 in terms of the revenues of large multinational corporations. However, according to the Brookings (2013) "there was a deliberate effort to create a more sustainable private-sector-led economy instead of relying on state-owned companies. The city now also has strong domestic financing capacity for small and medium-size enterprises to access."

Against the backdrop, in this analysis we reveal those factors that may contribute to the further economic and social development of Shenzhen. In the first part of the paper we focus on Shenzhen's current and future role in the Pearl River Delta, then in the second part we examine how the Sungang-Quingshuihe (SQ) neighbourhood can contribute to Shenzhen's growth. Our main goal is to replan SQ for a new vital centre of the city that can yield economic benefits for new IT and biotech start-up firms and can offer outstanding living conditions for all its inhabitants.

\section{Shenzhen's projected role in the Pearl River Delta: the theoretic Shenzhen Bay Area}

We envisage that Shenzhen will be more connected to the global economy overtaking the major gateway city status of Hong Kong. In the close future Shenzhen will become one of the world's leading IT and biotech centres thanks to the ongoing economic restructuring. Furthermore, as the natural connection between Hong Kong and the inner cities of the region, and between the sea and the mainland, Shenzhen will be the primary transportation hub of the PRD. Taking into account that Shenzhen is the headquarter of significant regional banks, financial service and real estate firms, moreover it hosts the Shenzhen Stock Exchange the city can be one of the main financial centres in China, and the most important one in the PRD.

All these projections can contribute to the creation of the Shenzhen Bay Area (SBA), the Chinese equivalent of the San Francisco Bay Area (SFBA). Ac- 
cording to our calculations the latter is the most significant R\&D centre in the world (on the basis of the companies ranked by the European Union) (EU 2014), moreover its economic structure is very similar to that of Shenzhen. For example, the five main industrial sectors (ICB-3D) of the SFBA as measured by its R\&D output are Technology Hardware \& Equipment (52\%), Software \& Computer Services (33\%), Pharmaceuticals \& Biotechnology (5\%), General Retailers (3\%), and Health Care Equipment \& Services (2\%), while in Shenzhen Technology Hardware \& Equipment (70\%), Software \& Computer Services (10\%), Electronic \& Electrical Equipment (9\%), Banks (7\%), and Health Care Equipment \& Services (2\%) are the most important sectors. Furthermore, San Francisco (as part of the SFBA) was the fourth greatest command and control centre in the United States in 2012 (like Shenzhen was the fourth in China), and was ranked third in the financial sector just behind New York and Washington DC (Csomós 2012, Csomós 2013).

However, it is a significant difference between the two areas that SFBA consists of only three major cities by population (San Jose: 1,000,536; San Francisco: 837,442; Oakland: 406,253), while the potential Shenzhen Bay Area can consist of very similar cities in terms of population (e.g. Guangzhou: 12,700,800, Shenzhen: 10,680,000; Hong Kong: 7,061,200; Dongguan: 8,220,237; Foshan: 7,194,311). Therefore, both two areas can be regarded as polycentric urban agglomerations. However, while in the SFBA there are only some major cities with special administrative function (each of them is county seat) and larger population, in the potential SBA we cannot single out any cities regarding their population or function. Of course, as the capital of Guangdong Province (which contains the PRD) and one of the National Central Cities of China Guangzhou has a special administrative role, however, the province has limited influence on Shenzhen as it is one of the 16 sub-provincial cities. Furthermore, as Timberlake et al. (2014) assert "in the 1980s and 1990s, Guangzhou's role as 'dragonhead' in the region was eroded by the rise of Shenzhen and the fast industrialization of other cities in the Pearl River Delta." Therefore, the most important feature of the region's leading city can be its economic power.

We think SBA is not just a dream, because there are some evidences that SBA (or a smaller region inside the PRD) has been forming for a while. In this region the close economic interconnection between Shenzhen and Hong Kong, as seed of the SBA, plays a key role. Moreover, an integration plan has already been officially put forward (Bauhinia Foundation Research Centre 2007, Qiao 2015) For example, Forrest et al. (2004) think that "the rapid expansion and development of Shenzhen and its interconnectedness with
Hong Kong have also drawn some commentators to argue that this rampant urbanisation is creating one of the major megacities of the world." Chen and de'Medici (2012) named the Shenzhen-Hong Kong city dyads as Shen-Kong innovation rim because of their interconnected financial system and high-technology and high-end industries. Shen (2014) argues that Hong Kong uses Shenzhen as a base for its cross-boundary activity, e.g. Hong Kong banks have set up branches in Shenzhen to expand their services. One of the Shenzhen Municipality's major developments is the Qianhai Shenzhen-Hong Kong Modern Service Industry Cooperation Zone which will focus on four main aims: 1) Qianhai will aim to facilitate innovation in the modern service industry; 2) it will aim at becoming a hub of modern services and modern service developments; 3 ) it will be a pilot area for closer cooperation between mainland China and Hong Kong; 4) and it will be a facilitator in the industrial reform and sustainable economic development of the PRD.

Shenzhen and Hong Kong have close interconnection regarding their traffic system (McNeil 2014), however, it needs further developments. "A rail connection between Hong Kong and Shenzhen airports is important for the safeguarding of Hong Kong's airport: Hong Kong airport is the heart of Hong Kong and at present, there is only one connection through to Hong Kong Island. If the Tsing Ma Bridge were to be affected by factors such as a natural disaster, Hong Kong airport would be paralysed, and its overall safety would be threatened, which in turn would affect the safety of the South China region. In addition, by establishing a rail connection between the airports of Hong Kong and Shenzhen, the flow of people between the two cities would be effectively promoted, creating a Hong Kong-Shenzhen super air hub that would be the focus of global attention. Moreover, this railway should be connected to the national high-speed railway network now under planning to strengthen the strategic position of a Hong Kong-Shenzhen Metropolis as South China's high-speed railway terminal (Bauhinia Foundation Research Centre 2007: 10-11)."

Of course there are some critiques who are against the integration, however, they mostly concerned about political issues. Shen (2014) states, that "Hong Kong and Shenzhen have many differences which may make it difficult to achieve full integration. Many Hong Kong and Shenzhen residents consider that the different value and political systems in two cities are main barriers of Hong Kong-Shenzhen integration."

After all Shenzhen and Hong Kong has been interconnected in many ways, especially regarding their economies, transportation systems, financial industries, even their high-tech sectors. The Hong Kong-Shenzhen Metropolis has almost 18 million inhabitants which makes the metropolis the largest city in the PRD. We 
think that the closely interlocked Hong Kong-Shenzhen Metropolis can be a seed of the Shenzhen Bay Area, an economically fully integrated zone within the PRD.

\section{Sungang-Quingshuihe neighbourhood as the new innovative growth centre of Shenzhen}

In the close future Shenzhen is supposed to be one of the most important global cities in the world, the primary gateway of the Chinese economy, an international centre of the information communication industry, an emerging focal point of biotechnology, the headquarters of large innovative multinational corporations, the centre of finance and advanced producer services, the driving force of the Pearl River Delta, the seed of the Shenzhen Bay Area, and a high-tech city where living conditions perfectly meet all the requirements of a modern era. Of course, Shenzhen has already started out on this path. The question is that how the Sungang-Quingshuihe (SQ) neighbourhood will look like in the future Shenzhen, and what its role will be.

We think SQ will be one of the most innovative parts of Shenzhen with entirely new functions. This is our vision about the future SQ:

- SQ is the home of a new higher education institution which primarily focuses on information com- munication technologies. This medium-sized, highly prestigious research university attracts academics, researchers and, of course, students from all over the world. This makes SQ an internationalized and multicultural site of Shenzhen.

- The university is significantly involved in the high-tech industry, therefore, innovations developed by the researchers of the university are delivered to the industry in a relatively short period. Chinese and foreign multinational corporations relocate their R\&D centres to SQ. Furthermore new start-up companies are launched in cooperation with Shenzhen Municipality, the university, and multinational corporations.

- SQ hosts a large hospital which, in cooperation with the research university, is the regional centre of computed tomography (CT). New start-up companies have been launched to develop hightech CT devices. The hospital in SQ is an important node of the hospital-based community health centres network the establishment of which is of high priority in Shenzhen (Zhang et al. 2011).

- This international environment with highly skilled labour force requires special living conditions. In both the southern and northern part of SQ there are apartments for middle-class communities. Local residents intermingle with newcomers creating a varied society.

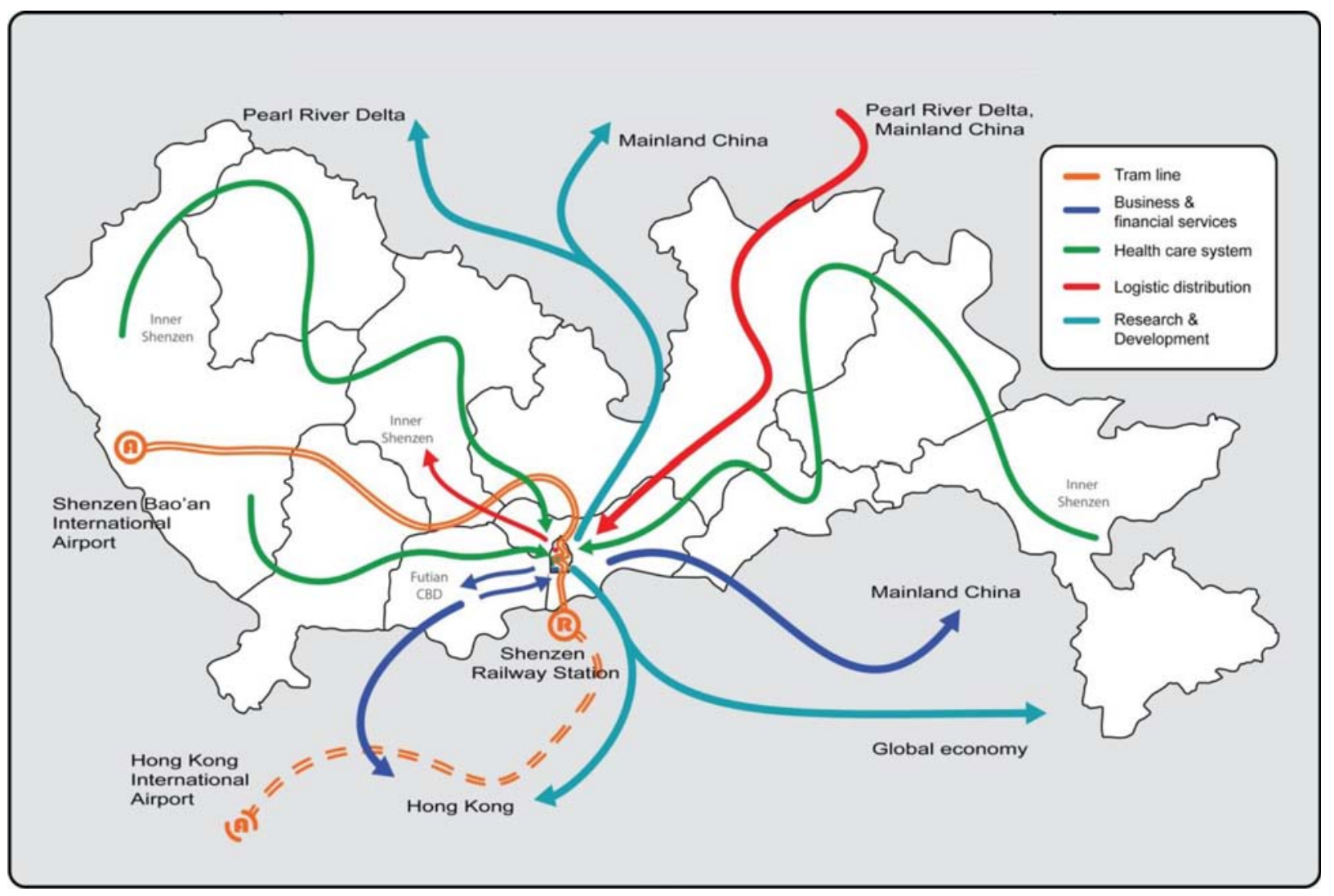

Fig. 1. New inner and outer city connections of Sungang-Quingshuihe 
- Urban villages are revitalized, renewed and rebuilt in order to satisfy all the requirements of the middle-class communities.

- The transportation system is replanned. The most important means of public transportation are trams which use train lines but they also have new lines going across SQ. Car traffic is reduced in the area, contrarily the use of bicycles are encouraged. There are many new bicycle roads all around SQ.

- The neighbourhood is surrounded and crossed by green corridors and parklands that provide a network for walking and running.

- Because most new inhabitants of SQ do office work for living (teaching, research and medical work), it is of a great importance to ensure the possibility of doing sports, e.g. running, Nordic walking, cycling in green corridors and in the Honghu park, rowing on the fishing pond.

- There is a large intermodal station in SQ, which combines various transportation options. The main aim of it is to reduce dependence on automobile and increase the use of public transport: trams, tram-trains, buses and bicycles. It makes possible for passengers to reach Shenzhen Bao'an International Airport, Hong Kong International Airport, and all larger train stations in a short time. $\mathrm{CO}_{2}$ emission is significantly reduced in SQ. It is an important issue because, according to Zhang et al. (2014), $\mathrm{CO}_{2}$ emitted during industrial fossil-fuel consumption and by the transportation sector has been gradually increasing in Shenzhen.

- SQ has different kind of connections with other cities of the PRD, the global economy through Hong Kong, and mainland China (Fig. 1).

- The intermodal station also serves as a large mall and some warehouses have been rebuilt into shopping centres.

- Solar panels are used on flat roofs in order to reduce the energy dependency of SQ.

- A new bed has been given to Buji River which is driven through close to the train lines. There are different solutions applied for cleaning the river before reaching Honghu Park.

Summarizing what has been said, the Sungang-Quingshuihe neighbourhood is a liveable area of Shenzhen with new and modern functions for international residents who work in higher education, ICT, medical services, $\mathrm{R} \& \mathrm{D}$ centres of multinational corporations, and research-oriented start-up companies. Local residents intermingle with this middle-class community. Some of them keep their former jobs, but most of them can find new jobs, and a more comfortable life.

\section{The main aims of planning and the most important phases}

In this vision, we are focusing on the re-planning process of the Sungang-Quingshuihe (SQ) neighbourhood. Our goal is to create functionally defined areas that have strong connections by all means of transportation, socially serve each other, efficiently function for the economic environment, and have an overall ecological system. Some of these areas can be shaped from existing buildings and infrastructure by renewal and expansion under brownfield development. Nevertheless, there are also some areas that are not suitable and appropriate in the long term for serving the social and economic needs of the city. Beyond the full-scale renewal of SQ, our intention is to integrate these areas into the future urban structure of Sungang-Quingshuihe (Fig. 2).

Before starting the design process, we think it is essential to conduct the high-voltage lines through the underground public utility tunnels in order to ensure a healthy environment. Without this measure, not only these two districts, but the entire city would remain unlivable and unhealthy.

\subsection{Transportation}

The basis of human-scale urban formation is pedestrian permeability. It means an interconnected square system that is independent from roads and highways for mechanized traffic. In certain cases where these systems cross each other, active solution can be found to drive traffic into tunnels, and allow pedestrians to walk over them so as to keep transportation continuous (Fig. 3). The directions and shapes of the roads should be aligned with the functional areas thus avoiding traffic jams and unnecessary pollution. We have foreseen with at least 12-meter-wide pedestrian walkways including lines of trees by the roads and sufficient room for cyclists.

We have kept the main highways and busiest roads, but added new low traffic lines to them by using roundabouts to maintain the continuity of circulation. We have also terminated certain lines as they caused excessive fragmentation. Taking all the above components into consideration, we have created a purposive road system that is capable of serving the future functions of SQ.

The current conditions of the railway site are rather neglected causing excessive noise in the district. Against this noise pollution, we have used a site enclosed by a sound-proof barrier. The establishment of the manufacturing area has allowed us to optimize and redefine the zone of the railway lines.

We have developed a new tram line across SQ to provide fast access to various areas for the inhabit- 
ants of the city without any particular environmental stress. This new means of public transport can easily connect the southern part of the city with the Shen- zhen airport with its route passing through less integrated sections of the northern side, thus designating new areas for future development.

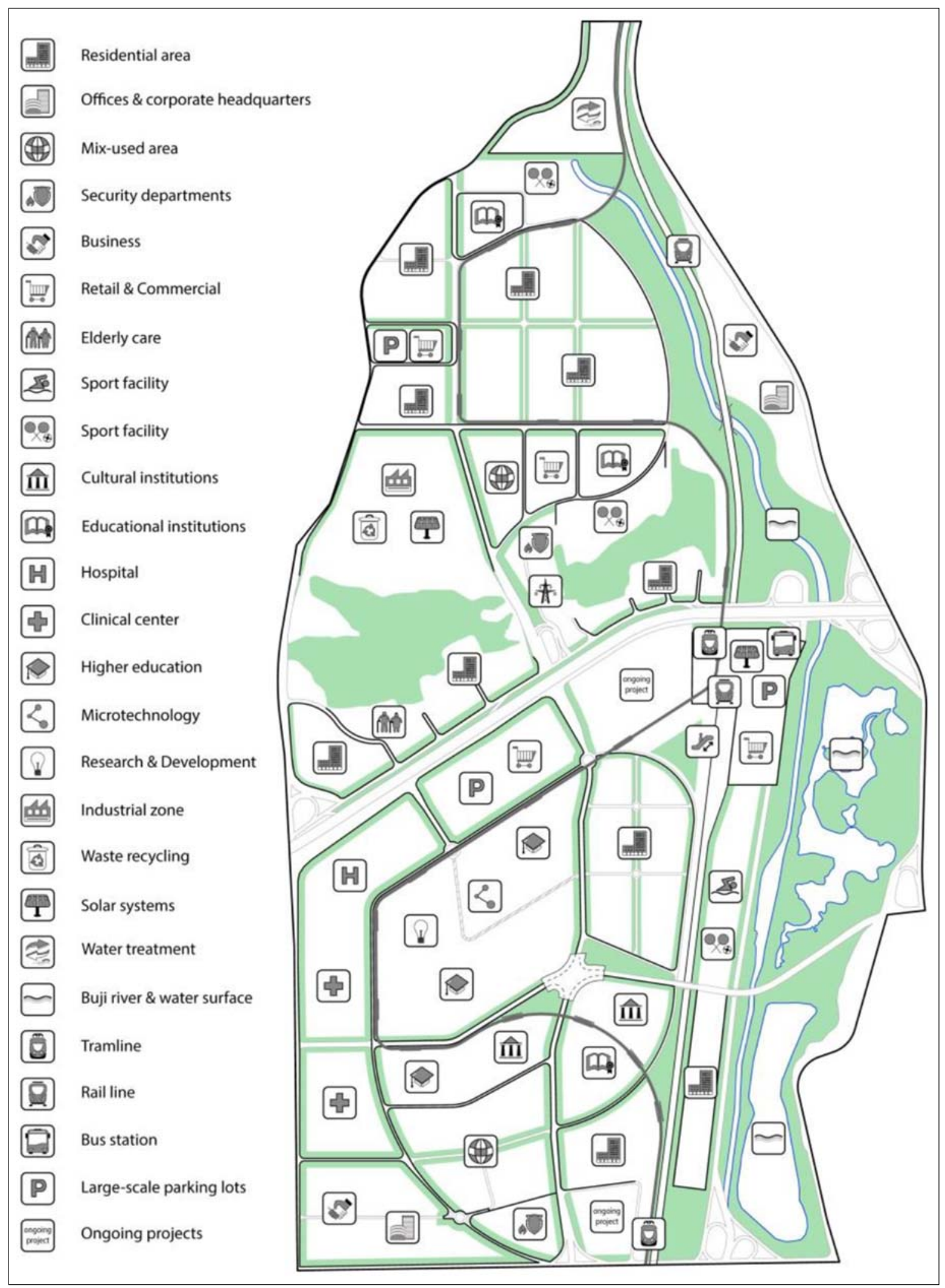

Fig. 2. Planned functions of Sungang-Quingshuihe 


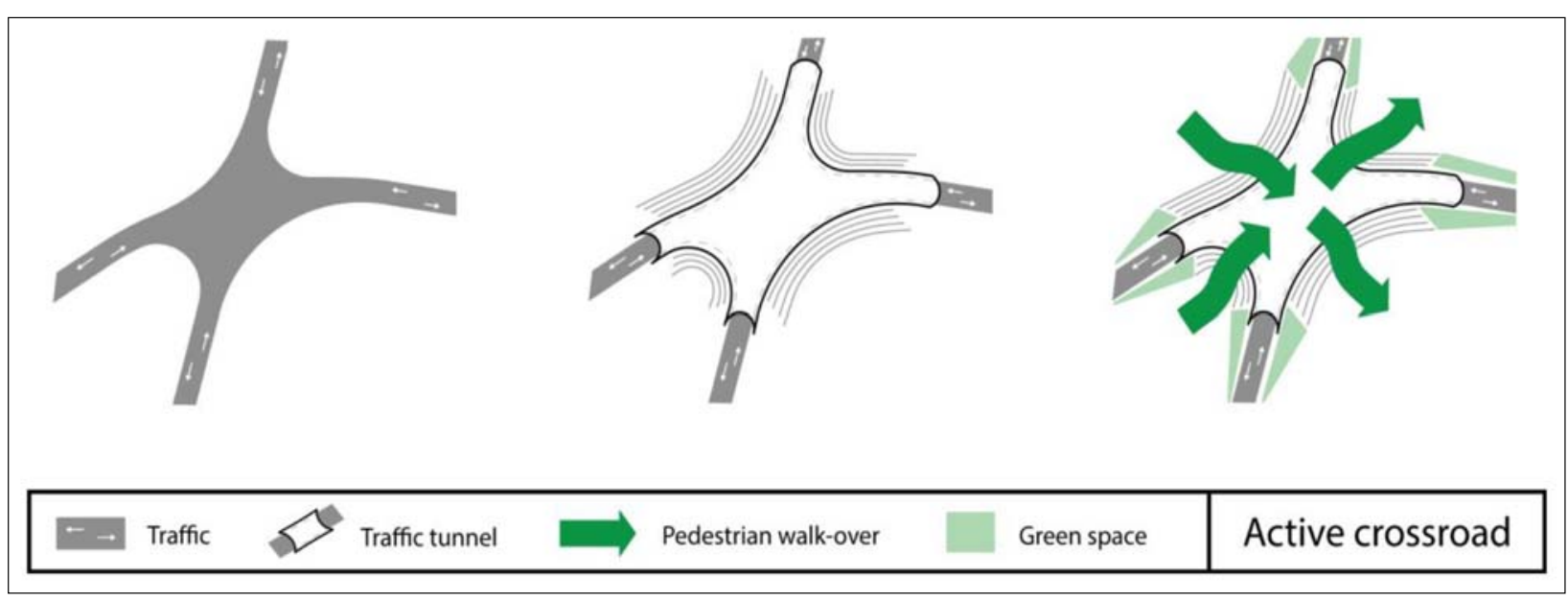

Fig. 3. Active crossroads for pedestrians and transportation means

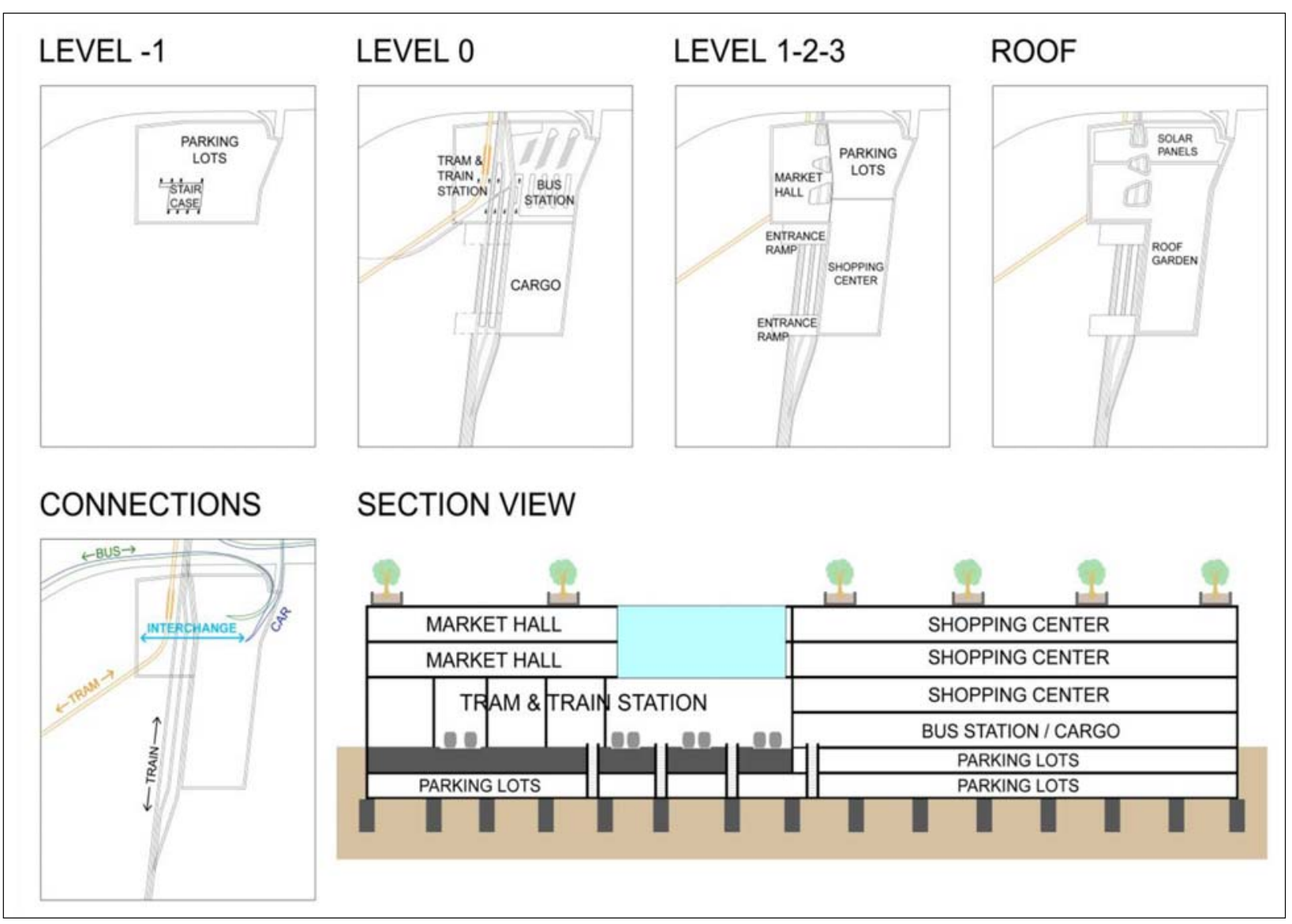

Fig. 4. The intermodal transit center

The intermodal center will have an immense role in the public transport scheme of Shenzhen. It is where the expressway will meet the railway, the local and intercity buses, as well as, the new tram line. It would be the key interchange of transportation devices in SQ. Further possibilities lie in the intermodal hub, e.g. a shopping center with entertainment services and a well-organized traditional market can be located here, too (Fig. 4).

\subsection{Economic environment}

Manufacturing and logistics center

Currently, a large portion of SQ is operated for manufacturing plants and warehouses. Most of them have turned out to be obsolete, not capable of producing the value as before, which is why only the most important sections should be left and consolidated into 
a single integrated and modernized logistic area that covers and provides supplies at an interdistrict scale. This logistic center can cater for other economic units of SQ, as well. With this optimization, new areas can be defined to serve other, more valuable features.

Information and Communications Technology (ICT)

In the light of the global economic trends and longterm plans of Shenzhen, a Research \& Development Center - a part of the university district - can function as a bridge between higher education and the stakeholders of the economic and scientific fields, which would secure a dominant position for SQ in the future. The key activity of this area would be to invent new, innovative solutions and designs with the use of cutting-edge technology.

\section{Clinical center}

The medical and health institutions of Shenzhen are difficult to access. Their locations lack any systematic approach in space. The linking and integration of the various departments into a single area under brownfield development would make the healthcare system more effective for the inhabitants, and improve its standards, too. Settling it close to the ICT center would back continuous progress and research opportunities in the field of microbiology and diagnostics.

\section{Business}

This is where SQ administration is accommodated with headquarters for local startups and other commercial actors directly related to ICT, the clinical and the logistics center.

\section{Retail}

There are mostly hypermarkets and larger commercial units serving residential needs both in the inner and outer districts. Brownfield development is a feasible option for these areas.

\section{Area of mixed use}

There is a broad range of services with hotels, exhibition and art showrooms, restaurants, retails, bars and nightclubs, small creative field offices and residential lofts, as well. This area would operate as a cultural and entertainment core of the districts with an intra-block alley.

\subsection{Social environment}

Residential areas

These areas contribute to the avoidance of the feeling of crowd, while creating comfortable and noise-free residential zones. To this end, the relative highness and proper distance of the buildings from each other have been the main aspects. The horseshoe shape with the lowest buildings on the bottom, rising higher to the top, can ensure it (Fig. 5). In the outer intermediate area, the location is the opposite, i.e. the central core can provide for small-sized public green space for inhabitants. These blocks centered on the park are also connected to the main green areas by ecological corridors.

Certain sections of the site are too close to busy highways and the railway line that results in uncomfortable living areas. In these cases, the construction of the plant enclosed with noise-proof barriers is vital, and can work effectively against the unwanted effects.

The ground floors of the buildings are perfectly suitable for small retail shops and restaurants.

\section{Educational institutions}

Principally, there are primary and secondary schools, as well as the associated institutions for the young local population. Facilitated access is a key aspect in these functions and it can be ensured by the new tram line.

\section{Sports}

To provide space for a healthy and active lifestyle, it is essential to dedicate some areas to leisure-time activities and sports. These areas provide indoor and outdoor courts and grounds for all kinds of sports.

\section{Homes for elderly people}

Each district has to prepare for social changes, especially when it comes to elderly age groups. The provision of secure and well-equipped homes for elderly people would help the tackling of social problems, and rejuvenate residential areas. Their closeness to healthcare institutions would also make them viable.

\section{Museums and cultural centres}

These features call for central locations to become visible and accessible for everyone. Having museums and cultural centres close to public transport facilities and surrounding them by other functional areas can 


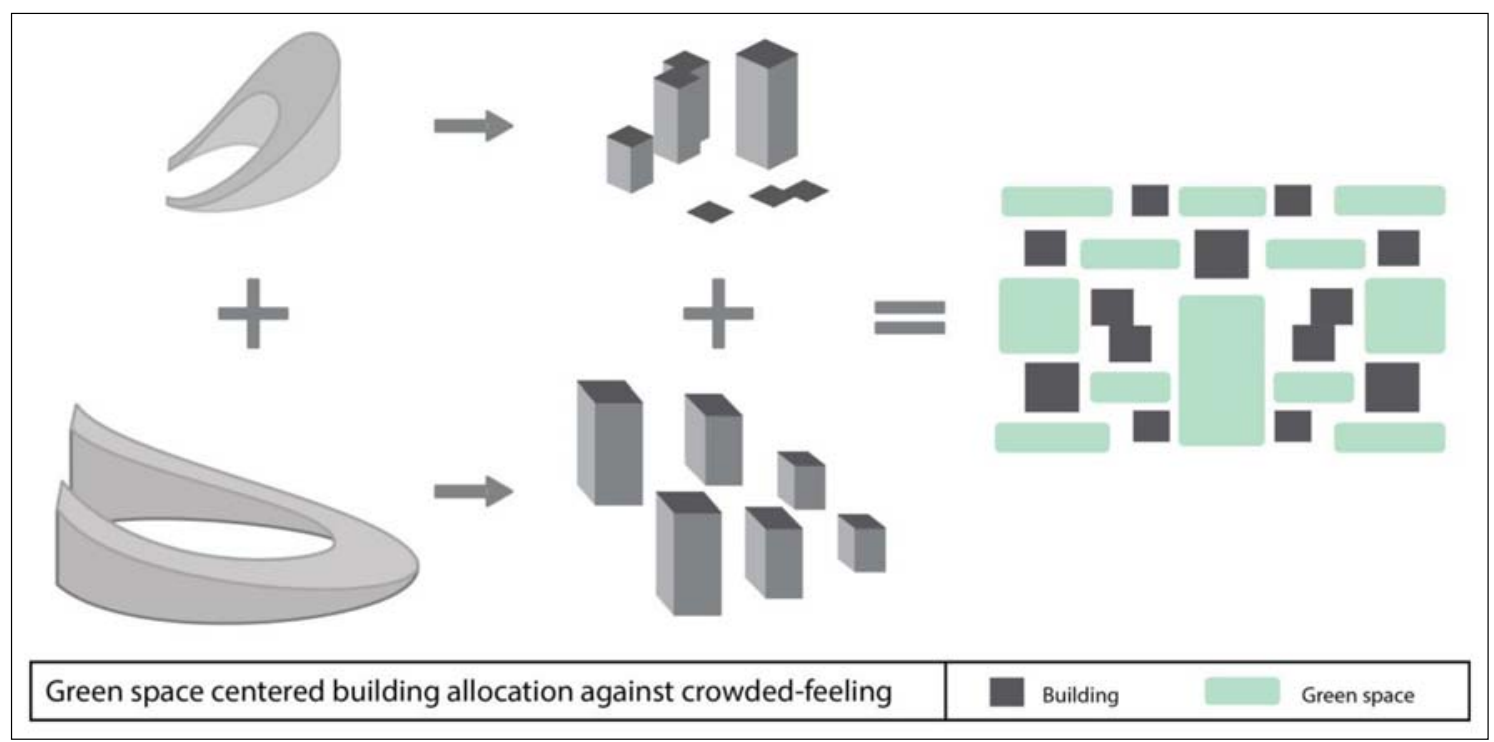

Fig. 5. Green space centered building allocation

help to make them popular and frequented sites of the district center.

\section{Security}

Multifunctional divisions such as the re-designed SQ need sophisticated public security. Headquarters for the police department and fire brigade are situated close to each other and by the main roads that cross the districts which lends them fast and easy access to any part of the area.

\subsection{Natural environment}

A well-arranged and properly kept ecological system is needed for a sound-balanced and clean urban area. This system has larger natural green spaces (in particular, Honghu Park and the mountains) and smaller urban parks, and parked squares. As an important aspect, these places should be directly linked to lines of trees so the assimilation process can effectively guarantee a fresh atmosphere with these green corridors. In certain cases, recultivation is an option to be seriously considered, as it can promote the strengthening of the local biodiversity.

The Buji River is in poor conditions in view of its physical properties and chemical contents. Being strongly polluted, it reaches Honghu Park in a mostly ducted channel, and does not form a part of the urban structure at all. A water treatment facility in the northern side of Quingshuihe can solve public utility problems, while ensuring the cleanliness of the river. By paying attention to this problem and relieving it from the given loads, the Buji River could be integrated into the texture of the district by making it usable for recreational purposes.
The natural environment also needs continuous support and development in order to achieve a livable urban design.

\subsection{Phases of the development}

Shenzhen has to assume responsibility for providing a healthy residential environment by creating proper legal conditions and regulations for construction and building activities. Based on such a regulatory framework, new and more livable spaces could be constructed, which would allow the city to make arrangements for and offer new places of residence in exchange for units in dilapidated areas and slums, financial compensation or housing opportunities in elderly people homes and other sections. By such centralized provisions, deteriorated conditions can be terminated. Such provisions would lead to a more comfortable urban texture. The main phases of development are (Fig. 6):

Phase I. The optimization of the area of manufacturing, warehousing and railway lines can make usable sections for changing function available. The renewal of these sections is significant in social and economic terms for the future of the city.

Phase II. Under brownfield development, the clinical center can be configured as it is necessary to serve the entire city.

Phase III. The newly formed sections can be put in use and re-arranged for the relocated inhabitants of other areas. Regarding the future innovative functions, the needs of the young and educated middle class should be revealed and satisfied.

Phase IV. Thereafter, dilapidated urban slums and villages can be rehabilitated, and further residential units with the associated institutions can be developed for the middle class. 


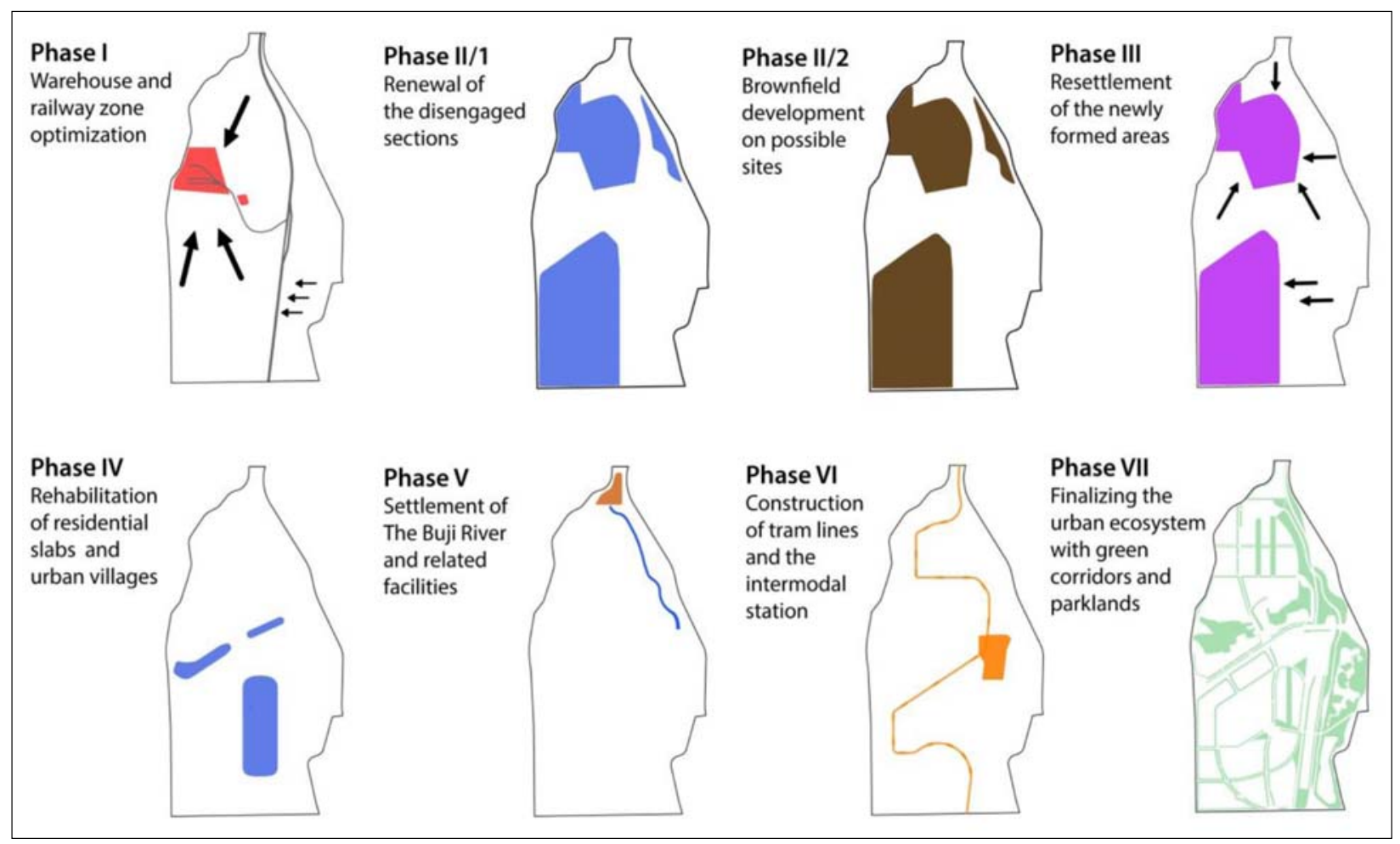

Fig. 6. Main phases of the development of Sungang-Quingshuihe

Phase $V$. The new water-course of the Buji River and the water treatment facility are fundamental elements of a sound and clean natural environment.

Phase VI. The creation of an intermodal center and tram line across SQ is a transport priority for improved local mobility, connection and easy interchange in between different means of transport en route to various parts of the city.

Phase VII. The ecological system of the area is to be finalized with green corridors (lines of trees) for linking up smaller urban green spaces and recultivated areas that would be harmonized with the broader natural areas.

\section{Summary}

Shenzhen is one of China's major cities regarding its economic performance, financial services, $R \& D$ activities, innovative industries, and command and control functions. However, thanks to its rapid economic development, it can be assumed that in the close future Shenzhen will be the leading economic centre of the Pearl River Delta surpassing such rivals as Hong Kong and Guangzhou. Shenzhen has already started out on a path to become a modern world city and it can be the seed of the Shenzhen Bay Area (SBA). SBA will not only be the manufacturing power house of China but also the major gateway of the world's leading economy. In this area Shenzhen will have key role as the centre of computer software design, in- formation communication industry, microelectronics and components manufacturing, electromechanical integration, and biotechnology. Shenzhen will move over from the current manufacturing driven economy to focus on high-tech industry exclusively. Shenzhen will organize the PRD's economic life and in order to do so the city will need a highly developed infrastructure, transportation system, financial and advanced producer services, research and development facilities and institutions, international research universities, hospitals, and a high-quality social and natural environment.

In this environment Sungang-Quingshuihe (SQ) neighbourhood will have a special role as a modern innovative growth center of the city. SQ will integrate all functions that are necessary for Shenzhen to achieve its main goals. We envisage that SQ will be a gradually growing higher education and medical centre of Shenzhen: the research university will receive students from all corners of the world, the modern clinical centre, the R\&D facilities of multinational corporations, and innovative start-up companies will employ newcomer researchers from all over the world. SQ will be an internationalized environment in which newcomers and the original residents will completely intermingle. This middle-class society will claim well-designated parklands, sport and retail facilities, and of course newly built modern apartments. Transportation will be reorganized, and will be centred in an intermodal station. The main transportation means will be the tram, 
which will also serve as a tram-train, and the bicycle. The natural environment (green corridors, parklands, the mountains, the Honghu Park, and the Buji River) will be redesigned and renewed, and will become the heart of SQ.

This draft plan can largely contribute to the rise of a perfectly liveable and dynamically growing Sungang-Quingshuihe neighbourhood.

\section{Acknowledgements}

An earlier draft of this paper was submitted to Global Schindler Award 2015.

This paper is supported by the János Bolyai Research Scholarship of the Hungarian Academy of Sciences.

\section{References}

Bauhinia Foundation Research Centre (2007), Building a Hong Kong-Shenzhen Metropolis. Executive Summary. http:// www.bauhinia.org/pdf/research/20070809/BFRC-HKSZES-ENG.pdf (last accessed: 21/01/2015)

Brookings (2013), The 10 Traits of Globally Fluent Metro Areas: Global Cities Initiative. Shenzhen. Brookings, Washington D.C.

Chen K., Kenney M. (2007), Universities/Research Institutes and Regional Innovation Systems: The Cases of Beijing and Shenzhen. World Development, 35(6), 1056-1074.

Chen J., Chang K.-T., Karacsonyi D., Zhang X. (2014), Comparing urban land expansion and its driving factors in Shenzhen and Dongguan, China. Habitat International, 43, 61-71.

Chen K., Chen G. (2014), The rise of international financial centers in mainland China. Cities, doi: 10.1016/j.cities. 2014.11.012

Cheng F., van Oort F., Geertman S., Hooimeijer P. (2014), Science parks and the co-location of high-tech small- and medium-sized firms in China's Shenzhen. Urban Studies, 51(5), 1073-1089.

Chen X., de'Medici T. (2012), From a fishing village via an instant city to a secondary global city: The "Miracle" and growth pains of Shenzhen special economic zone in China. In: Chen X., Kanna A. (eds), Rethinking Global Urbanism. Comparative Insights from Secondary Cities. Routledge, New York, 107-126.

Csomós G. (2012), GaWC Data Set 26: Global Command and Control Centres, 2006/2009/2012. http://www.lboro. ac.uk/gawc/datasets/da26.html

Csomós G. (2013), The command and control centers of the United States (2006/2012): An analysis of industry sectors influencing the position of cities. Geoforum, 50, 241-251.
EU [European Union] (2014), 2014 EU Industrial R\&D Investment Scoreboard. European Union, Luxembourg.

Forrest R., La Grange A., Yip N.-M. (2004), Hong Kong as a Global City? Social Distance and Spatial Differentiation. Urban Studies, 41(1), 207-227.

Harrison J., Hoyler M. (2015) Megaregions: foundations, frailties, futures. In: Harrison J., Hoyler M. (eds), Megaregions: Globalization's New Urban Form? Edward Elgar Publishing, Cheltenham.

Lo V.H.Y., Yeung A.H.W. (2004), Practical framework for strategic alliance in Pearl River Delta manufacturing supply chain: A total quality approach. International Journal of Production Economics, 87(3), 231-240.

McNeil D. (2014), Airports and territorial restructuring: The case of Hong Kong. Urban Studies. doi: 10.1177/ 0042098013514619

Morrison N. (2014), Building talented worker housing in Shenzhen, China, to sustain place competitiveness. Urban Studies, 51(8), 1539-1558.

Ng M.K. (2003), City profile: Shenzhen. Cities, 20(6), 429-441.

Qiao S. (2015), Small property, big market: A focal point explanation. American Journal of Comparative Law, 63(1), in press.

Shen J. (2014), Not quite a twin city: Cross-boundary integration in Hong Kong and Shenzhen. Habitat International, 42, 138-146.

Timberlake M., Wei Y.D., Ma X., Hao J. (2014), Global cities with Chinese characteristics. Cities, doi: 10.1016/j.cities. 2014.02.009

UN [United Nations] (2014), 2014 Revision of World Urbanization Prospects. United Nations, New York.

Yang C. (2014), State-led technological innovation of domestic firms in Shenzhen, China: Evidence from liquid crystal display (LCD) industry. Cities, 38, 1-10.

Yeh A.G., Yang F.F., Wang J. (2014), Producer service linkages and city connectivity in the mega-city region of China: A case study of the Pearl River Delta. Urban Studies, doi: 10.1177/0042098014544762

Zacharias J., Tang Y. (2010), Restructuring and repositioning Shenzhen, China's new mega city. Progress in Planning, 73(4), 209-249.

Zhang D., Mou J., Cheng J.Q., Griffiths S.M. (2011), Public health services in Shenzhen: A case study. Public Health, 125(1), 15-19.

Zhang W., Huang B., Luo D. (2014), Effects of land use and transportation on carbon sources and carbon sinks: A case study in Shenzhen, China. Landscape and Urban Planning, 122, 175-185.

Zhao S.X.B., Zhang L., Wang D.T. (2004), Determining factors of the development of a national financial center: The case of China. Geoforum, 35(5), 577-592.

Z/Yen Group (2014), The Global Financial Centres Index 15, March 2014. Z/Yen Group, London. 